\title{
Setor de Psicologia Escolar da Faculdade de Filosofia, Ciências e Letras de Ribeirão Preto - USP: primórdios e funcionamento até 1994
}

\author{
Vera Lúcia Sobral Machado
}

A Faculdade de Filosofia, Ciências e Letras de Ribeirão Preto foi criada pela Lei Estadual 5377 de 25/06/59, como Instituto Isolado do Ensino Superior do Estado de São Paulo e foi transformada em Autarquia de Regime Especial pelo Decreto Lei 191 de 30/01/70. Em 1975 foi incorporada a Universidade de São Paulo (USP) integrando-se ao Campus de Ribeirão Preto. A idéia básica de seu fundador, Dr. Lucien Lison, era constituir uma Faculdade de Ciências o que ainda se reflete nos cursos de Biologia, Química e Psicologia existentes nela.

Apesar de ser criada em 1959 os cursos somente começaram a funcionar a partir de março de 1964 e a estrutura curricular das primeiras turmas do Curso de Psicologia compreendia: Propedêutico:- Matemática, Introdução a Psicologia Experimental, Inglês (opt), Física, Biologia, Química. $2^{\circ}$ ano: Metodologia dos testes (Psicometria I) , Psicologia do Desenvolvimento I, Matemática, Psicologia Experimental I, Estatística I, Inglês (opt), Fisiologia Humana, Neurofisiologia, Psicopatologia Geral I, Psicologia Diferencial, Francês (opt). $3^{\circ}$ ano: Psicologia Social I, Psicologia Geral I e II, Psicologia Experimental II, Psicometria II, Psicologia do Desenvolvimento II, Estatística II. $4^{\circ}$ ano: Psicopatologia Geral II, Psicologia da Indústria I, Orientação Educacional e Profissional (opt), Administração Escolar, Psicologia Social II, Estatística III, Técnicas de exame e aconselhamento psicológico I, Psicologia da Personalidade I e II, Psicologia Social III (opt), Psicologia da Aprendizagem, Prática de Ensino em Psicologia, Didática Geral, Seleção e Orientação Profissional (opt). $5^{\circ}$ ano: Psicofisiologia (opt), Psicologia da Indústria II (opt), Ética Profissional, Técnicas de Exame e Aconselhamento Psicológico II e II, Psicometria III (opt), Introdução a Psicologia Clínica (opt), Questões aprofundadas em Psicologia da Personalidade (opt), Dinâmica de grupo (opt), Psicologia Escolar e Problemas de Aprendizagem I e II (opt), Monografia de conclusão de curso, estágio supervisionado.

Até 1971 as turmas ingressantes passavam por esta estrutura curricular que compreendia um ciclo propedêutico e um ciclo profissional e que exigia a elaboração de monografia para obtenção do certificado de conclusão de curso.

A disciplina Psicologia Escolar e Problemas de Aprendizagem fez parte do currículo do Curso de Psicologia da FFCL de Ribeirão Preto desde o seu início e sempre manteve uma característica teórico-prática, visando dar aos alunos a oportunidade de vivenciarem, em situações reais, o conhecimento da estrutura e funcionamento de Instituições educacionais e experenciarem o exercício de um papel profissional nesta realidade. Sua primeira docente Lúcia Helena Siqueira Barbosa, desenvolveu, em 1968, um programa que focalizava, no primeiro semestre, um conteúdo teórico sobre: caracterização da área, funções do psicólogo escolar, interação social em sala de aula, problemas de aprendizagem, características do professor e do ensino e importância da saúde mental na escola. No segundo semestre foram desenvolvidas atividades práticas em duas escolas públicas da cidade. No ano seguinte a responsável pela disciplina foi Filhinha Rodrigues Alves Maffeis e, embora mantida a ocorrência da parte teórica e da parte prática na forma de estágio, o conteúdo abrangeu tópicos diferentes compreendendo: conceituação da educação, princípios da educação, o 
papel da escola na formação do indivíduo, o papel do psicólogo junto a unidade escolar, problemas gerais do currículo, o problema da avaliação do trabalho escolar. A parte prática consistiu na realização de trabalho de observação e aconselhamento escolar de alunos do curso secundário de uma escola pública da cidade. Em 1970 e 1971 a disciplina ficou sob responsabilidade de Geraldina Porto Witter e mostrou uma tendência mais próxima à da primeira programação focalizando: caracterização da área de estudo, papel do psicólogo escolar, variáveis relativas ao aluno, ao ambiente, a tecnologia do ensino e matérias escolares relevantes ao estudo da Psicologia escolar e problemas de aprendizagem, mas acrescentando como tópico: aplicação da análise experimental do comportamento em sala de aula. A parte prática compreendeu além da observação dos alunos em situação escolar um treino no uso de estímulos discriminativos adicionais para controle de alguns padrões de respostas, aplicação de sistemas motivacionais em sala de aula e controle de respostas através de material usado para instrução. Neste período vários trabalhos de pesquisa foram realizados, no setor, sob orientação desta docente e apresentados como monografia de conclusão de curso: "Efeito da mudança de distribuição de móveis em sala de aula na aprendizagem de geometria"; "Influência do reforço na emissão de respostas criativas em escolares"; "Comparação entre realização no teste Metropolitano de Prontidão e em aprendizagem de discriminação"; "Efeito do treino no comportamento verbal"; "Eficiência de variações na técnica de emparelhamento com um modelo na discriminação visual de sílabas"; "Estudo experimental de um instrumento para detectar reforços".

A partir de 1972 até 1994 a disciplina ficou sob minha responsabilidade mantendo um conteúdo teórico muito semelhante ao que estava vigorando, mas passando por mudanças estruturais na forma de divisão de conteúdos por semestres e no oferecimento de oportunidades de estágio. Assim, até 1971, a disciplina Psicologia Escolar e Problemas de Aprendizagem, compreendendo dois semestres, previa na sua carga horária, como já descrito, uma parte prática que ocorria durante o segundo semestre do seu início e cuja realização conferia aos alunos horas de estágio exigidas para sua formação. Isto acontecia com várias disciplinas da estrutura curricular. A partir deste ano no entanto, em atendimento ao artigo 16 da lei 4119/62 que dispõe sobre os cursos de formação em Psicologia e que obriga as Faculdades que mantiverem cursos de Psicólogos a "organizar serviços clínicos e de aplicação à educação e ao trabalho, orientados e dirigidos pelo conselho de professores do curso, abertos ao público, gratuitos ou remunerados", foi criado o Centro de Psicologia Aplicada com as seguintes finalidades: a) supervisionar estágios, proporcionando treinamento profissional aos alunos de graduação do curso de psicologia; b) empreender pesquisas nos diversos campos da psicologia aplicada e c) atender a comunidade.

Esse fato aliado a uma solicitação crescente de instituições educacionais para ajuda no enfrentamento de problemas, ao interesse de alunos para realizarem estágios nestas instituições e a disponibilidade do docente para instalar, organizar e supervisionar o trabalho a ser desenvolvido alicerçaram a implantação e o funcionamento de um Serviço de Psicologia Escolar. Assim, inicialmente restrito a disciplina Psicologia Escolar e Problemas de Aprendizagem desenvolvida em dois semestres o setor se expandiu: a) oferecendo aos alunos a possibilidade de realizarem, em instituições educacionais, atividades de estágio por dois semestres consecutivos, além de cursarem as disciplinas Psicologia Escolar e Problemas de Aprendizagem I e II; b) ampliando o número de instituições atendidas, continuando a divulgar a importância do papel do psicólogo nestas instituições e a mostrar as possibilidades de atuação deste profissional. 
A Serviço atendeu a várias escolas estaduais e municipais, parques infantis, núcleos assistenciais tendo como objetivos gerais: a) estabelecer entre a universidade e a comunidade um trabalho de cooperação e integração de forma a proporcionar a ambas os benefícios de uma ação continuada; b) desenvolver um trabalho em cooperação procurando analisar as situações e sugerir ações visando o desenvolvimento dos educandos e aperfeiçoamento dos professores e c) pesquisar sobre diferentes fatores envolvidos no contexto educacional de forma a obter melhor compreensão e produção de conhecimento relevante para futuras atuações.

De uma forma geral pode-se caracterizar o Serviço como desenvolvendo:

1. Estágios - proposição, coordenação e orientação de atividades possibilitando aos alunos: a) exercer, sob supervisão, um trabalho profissional numa área que, gradativamente se amplia; b) conhecer melhor a realidade escolar. a desenvolvimento destas atividades iniciava-se a partir de uma solicitação de ajuda colocada pela escola. Eram discutidas então possibilidades de atuação abrangendo horários, espaço disponível, pessoas interessadas e duração do trabalho. A participação dos alunos envolvia: caracterização da situação e do problema colocado através de observações e entrevistas, análise conjunta dos fatos através de reuniões, planejamento de atividades a serem desenvolvidas e ajuda direta na implantação das mesmas. Todas as atividades eram supervisionadas, registradas e discutidas e muitas delas relatadas em Congressos.

2. Apoio à comunidade Atividade diretamente decorrente da anterior que propiciava o atendimento a solicitações de instituições educacionais procurando: levantar informações para caracterização da situação e de fatores envolvidos nas necessidades apontadas; promover discussão, orientação e apoio a professores, pais e alunos para busca de resolução dos problemas enfrentados. Este apoio era realizado, na maioria das vezes, através das atividades de alunos estagiários.

Aqui cabe salientar que a procura pelo Serviço foi sempre maior do que a possibilidade de atendimento devido a dois problemas: a inexistência de pessoal fixo suficiente para manutenção do Serviço e a oscilação, a cada ano, de alunos interessados na realização de estágio na área, que ocorria face a não obrigatoriedade de cumprimento de atividades na mesma dificultando qualquer planejamento de ampliação.

3. Formação continuada - atendimento a profissionais já atuantes no mercado de trabalho através de atualizações teóricas e orientações práticas. Esta atividade foi implantada devido a solicitação de profissionais que enfrentavam dificuldades no seu trabalho e buscavam orientação. Neste contexto eram organizados grupos de discussão e atualização.

4. Pesquisas - desenvolvimento de trabalhos de investigação científica apresentados na forma de monografias, relatos em congressos, artigos em revistas especializadas. De maneira geral, estes trabalhos focalizaram condições associadas ao processo ensino - aprendizagem em situações formais de escolarização, bem como questões ligadas ao trabalho do Psicólogo Escolar e podem ser assim caracterizados: a) análise de aspectos relacionados ao ensino e aprendizagem da leitura e da escrita- Ex.: "O teste de prontidão para a leitura de Eloah Kunz na avaliação de crianças de baixo nível sócioeconômico". b) Interações, expectativas e representações como mediadoras das relações na escola- Ex. " Concepções dos adolescentes sobre seu desenvolvimento e sua vida escolar"; c) Análise de Serviços e intervenções do Psicólogo em Instituições educacionais- Ex.: "Um serviço de consultoria a professores do ciclo básico como forma alternativa ao encaminhamento de crianças à educação especial"; d) Dificuldades de aprendizagem- Ex.: "Dificuldades de aprendizagem e a relação interpessoal na prática pedagógica" ; e) Adaptação à escola- levantamento e caracterizaçãoEx.: "Ambientação à escola: atuação junto a um grupo de crianças iniciando o ciclo básico". Cabe aqui comentar que a instalação deste serviço criou necessidades de ampliação de pessoal e assim o 
setor passou a contar, em 1974, com mais uma docente Márcia Regina Bonagamba Rubiano que ajudou a desenvolver o conteúdo teórico- prático e as atividades de estágio. O conteúdo teórico de Psicologia Escolar e Problemas de Aprendizagem I manteve a mesma tendência teórica já descrita até 1985 e a partir deste ano foram aprofundadas as discussões sobre os diferentes papéis a serem assumidos pelo psicólogo escolar em instituições educacionais. O conteúdo programático de Psicologia Escolar e Problemas de Aprendizagem 11 continuou mais voltado para um treinamento prático dos alunos focalizando tópicos teóricos sobre: avaliação na escola aspectos preventivos e remediativos, orientação a terceiros, aspectos relacionados a pré- escola e a alfabetização, intervenção precoce, programas para desenvolvimento da prontidão, programas relacionados ao favorecimento do desenvolvimento infantil e associando estes conteúdos a tarefas de observação ou elaboração prática de propostas a serem implantadas.

De uma maneira geral podemos afirmar que, embora apresentando variações nos conteúdos teóricos em decorrência de mudança do docente responsável, evolução do conhecimento, ajustes considerando-se outras disciplinas inseridas no currículo, a orientação seguida foi sempre a mesma de apontar a ação preventiva como prioritária e de enfatizar o trabalho junto aos professores, seja de assessoria, colaboração e formação em serviço como mais importante.

Um aumento de alunos interessados na área e também uma procura crescente de atendimento por várias instituições educacionais foram fatores que determinaram novas necessidades e a partir de 1989, o Setor de Psicologia Escolar passou a contar com Maria das Graças Bonfim, técnica especializada em Psicologia que veio contribuir na tarefa de supervisão de estágios e atendimento à comunidade. Neste ano as atividades de estágio passaram a integrar a estrutura curricular como disciplinas formais passando a denominação de Atuação do Psicólogo em Instituições Educacionais I e II. Assim, até 1994, o setor abrangia as disciplinas Psicologia Escolar e Problemas de Aprendizagem I e II e Atuação do Psicólogo em Instituições Educacionais I e II e um Serviço de Psicologia Escolar funcionando junto ao Centro de Psicologia Aplicada.

Aqui está, em linhas gerais, o relato sobre como este Setor começou e como desenvolveu, no decorrer deste anos. A vivência, na quase totalidade deste trajeto, seja como, aluna, colaboradora e docente responsável, permite dizer que ele se consolidou, se projetou, formou pessoas, deixou marcas. Evidentemente falhas ocorreram, dificuldades estiveram presentes, algumas resolvidas outras não, mas fica a certeza de que uma história, compartilhada por muitos, foi construída. 